\title{
Unhealthy Stem Cells: When Health Conditions Upset Stem Cell Properties
}

\author{
Laura M. Pérez ${ }^{\mathrm{a}, \mathrm{b}} \quad$ Beatriz de Lucas ${ }^{\mathrm{a}, \mathrm{b}} \quad$ Beatriz G. Gálvez ${ }^{\mathrm{a}, \mathrm{b}}$ \\ aUniversidad Europea de Madrid, Madrid, 'bInstituto de Investigación Hospital 12 de Octubre (i + 12), \\ Madrid, Spain
}

\author{
Key Words \\ Stem cells $\cdot$ Niche $\cdot$ Alterations $•$ Disease $\cdot$ Cell therapy
}

\begin{abstract}
The stem cell field has grown very rapidly during the last decade, offering the promise of innovative therapies to treat disease. Different stem cell populations have been isolated from various human adult tissues, mainly from bone marrow and adipose tissue, but many other body tissues harbor a stem cell population. Adult tissue stem cells are invariably found in discrete microenvironments termed niches, where they play key roles in tissue homeostasis by enabling lifelong optimization of organ form and function. Some diseases are known to strike at the stem cell population, through alterations in their specific microenvironments, making them non-viable. Furthermore, it has been shown that a transformed stem cell population could prompt the development of certain cancers. This review focuses on the potential negative aspects of a range of diseases on the activity of stem cells and how their potential use in cell therapies may be affected.

(C) 2018 The Author(s)

Published by S. Karger AG, Basel
\end{abstract}

\section{Introduction}

Adult stem cells (ASCs) are considered the linchpins of tissue homeostasis in mature organs, enabling lifelong optimization of organ form and function [1]. ASCs are localized to specific microenvironments known as niches [2], which are anatomically defined and comprise extracellular matrix (ECM) components, cells and diffusible factors that together maintain and control stem cell activity. The study of ASCs within their native niche is important because of its direct influence on stem cell behavior.

Stem cell therapy is defined as the use of stem cells to treat or prevent a disease or condition, exemplified by the use of bone marrow-derived stem cells for hematopoietic reconstitution. Cell-based therapies can be classified into two types according to the source of the stem cells: autologous stem cell therapy, where stem cells are first collected from a patient and then returned, and allogeneic stem cell therapy, where stem cells originate from a genetically similar but not identical donor. 
In this review, we focus on recent discoveries highlighting the interplay between disease and the stem cell niche, which can lead to a decline or a dysfunction in the stem cell pool and may therefore complicate their use in cell-based therapy.

\section{Properties and hierarchy of stem cells}

Stem cells are undifferentiated long-lived cells characterized by two important features. They have an intrinsic self-renewing capacity, by which they divide asymmetrically and symmetrically to perpetuate the stem cell pool throughout life. Also, they can give rise to several mature cell lineages under appropriate conditions, a property known as multilineage potential or differentiation potency [3].

Several stem cell types are known to exist and they can be classified hierarchically according to their multilineage potential (Fig. 1), commencing with the totipotent zygote that has the greatest differentiation potential, followed by embryonic stem cells (ESCs), which are restricted to embryonic lineages [4], and ASCs, which comprise principally hematopoietic (HSCs) and mesenchymal (MSCs) stem cells [5]. A simplified classification of stem cells with respect to their origin and their abilities to differentiate into tissue lineages is shown in Fig. 1.

Embryonic stem cells are derived from the inner cell mass of a blastocyst that forms early during embryogenesis [6]. ESCs have unlimited potential to produce almost every cell type in the body and are considered pluripotent. ESCs retain an extraordinary plasticity to produce specialized cell types and they can be cultured indefinitely in an undifferentiated state [4]. These properties make them a particularly attractive choice for cell therapy. Despite the growing knowledge about their enormous potential and promise, ethical concerns may limit their exploitation for cell-based therapeutic applications.

Adult stem cells, which are the central focus of this review, are multipotent stem cells that can be found in a broad range of tissues [7]. Indeed, it is thought that most organs and tissues contain a pool of multipotent stem cells to regenerate or replace lost or damaged cells [8]. Not only are these cell reservoirs responsible for normal tissue maintenance, but they are also considered to be prime targets for modification (genetic and epigenetic alterations). To date, ASCs have been derived from bone marrow, peripheral blood, blood vessels, brain, skeletal muscle, epithelia of the skin and digestive system, cornea, retina, liver, and pancreas.

Hematopoietic stem cells are unquestionably the best characterized multipotent stem cell population and were first isolated from bone marrow almost 30 years ago [9]. Although HSCs predominantly reside in the bone marrow, they can also be found in umbilical cord blood and in peripheral blood [10]. HSCs function to generate all blood cell types, both myeloid and lymphoid

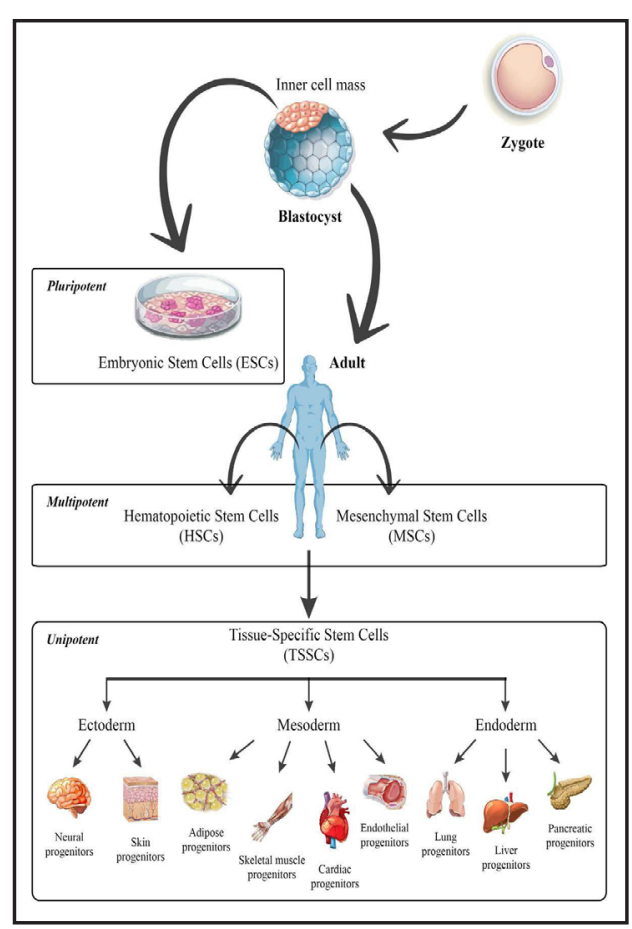

Fig. 1. Stem cell lineages. Stem cells are classified into three main types: pluripotent stem cells, which are embryonic stem cells (ESCs) collected from the blastocyst inner cell mass; multipotent stem cells, which include hematopoietic stem cells (HSCs) and mesenchymal stem cells (MSCs); and unipotent stem cells, which are tissue-specific stem cells (TSSCs) isolated from various tissues and use many times equally to adult stem cells (ASCs). 
lineages, to maintain proper hematopoietic function [11]. It is now generally acknowledged that HSCs can be purified with ease because they specifically express the CD34 antigen on their surface [12].

Mesenchymal stem cells are a type of nonhematopoietic ASC that give rise to multiple mesenchymal lineages, such as cartilage, bone and fat. The first evidence that they were present in the bone marrow was presented by Friedenstein and colleagues in the 1970s [13]. MSCs can be found in nearly all tissues and are generally located in perivascular niches [14]. The major MSC reservoirs include bone marrow [7], peripheral blood [15], adipose tissue $[16,17]$, lung $[18,19]$ and neonatal tissues [20]. MSCs have three main characteristics that make them ideal for the creation of off-the-shelf therapies. First, they have a remarkable ability to proliferate in vitro and differentiate into many (but not all) cell types. Second, they are endowed with migration and homing properties through which they can reach damaged tissues [21]. Finally, they exhibit immunomodulatory properties; they avoid allorecognition through the low expression of major histocompatibility complex (MHC) class I and the absence of MHC class II, and they generate a local immunosuppressive microenvironment through the secretion of cytokines [22]. Despite their ease of isolation using a combination of cellular membrane markers, there is, nevertheless, no unique marker to distinguish MSCs, as there is for HCSs.

Progenitor cells are the early descendants of ASCs and are principally found in specific tissues, leading to their designation as tissue-specific stem cells. They have the ability to differentiate into one or more cell type. The major differences between ASCs and progenitor cells are that progenitor cannot replicate indefinitely, and most progenitors are considered oligopotent $[23,24]$. Nonetheless, these differences are still unclear and the terms are often used interchangeably. Progenitor cells can be classified into different subtypes depending on their cell type of origin.

Mesenchymal progenitor cells are a committed lineage derived from MSCs and are present within a specific organ, giving rise to all mesodermal tissue [25]. These precursors are found mainly in adipose tissue, muscle or the vascular system. For example, preadipocytes/adipose progenitor cells (APCs) are present within adipose tissue and they are many times also called MSCs $[17,26]$. Satellite cells are dormant progenitors located at the periphery of skeletal myofibers that can be triggered to proliferate for self-renewal and to differentiate into myogenic cells. They have an important role in muscle regeneration $[27,28]$. Cardiac stem cells or resident cardiac precursors cells (CPCs) have been isolated from the heart based on their cell surface phenotype and play an important role in heart maintenance and can restore cardiac function $[29,30]$. Other examples include endothelial precursor cells, pericytes and mesoangioblasts, which can be isolated from the vascular system and are termed vessel-resident stem/progenitor cells [31]. Endothelial progenitor cells are multipotent cells within the vascular system and play a role in the regeneration of the endothelial lining of blood vessels [32]. Pericytes reside on the wall of blood vessels and function to maintain vessel integrity. They are now acknowledged as being functionally diverse and sophisticated and present a high differentiation capacity [33]. Mesoangioblasts are mesenchymal-like cells associated with the walls of the large vessels and express the marker of angiopoietic progenitors Flk1 [34]. Pericytes and mesoangioblasts exhibit many similarities.

Endodermal progenitor cells give rise to the gut tube and to all endoderm tissues. Recently discovered progenitor cells belonging to this group include lung, liver and pancreatic progenitor cells. Lung progenitor cells have been identified as small populations of lung resident cells that display stem cell features [35]. Several studies have shown that lung progenitors share some common characteristics with MSCs [19]. The existence of pancreatic progenitor cells, which possess abilities of self-renewal and multipotency, is controversial. Some research has demonstrated the presence of pancreatic duct cells expressing the transcription factor Pdx1 that are capable of self-renewal and differentiation into insulin-, glucagon- and somatostatin-producing cells [36, 37]. Liver progenitor cells have been located and isolated from livers of all donor ages. Evidence for the existence of 
diverse sources of liver progenitors has been found in biliary glands or near to the different hepatic ducts [38, 39].

Ectodermal progenitor cells give rise to ectoderm tissue, with skin and nervous system being the main representatives. This group comprises recently discovered neural and epidermal precursors. Studies have shown that some glial cells function as progenitors or neural stem cells (NSCs) [40], which are able to self-renew and generate the main phenotypes of the nervous system including neurons, astrocytes, and oligodendrocytes [41, 42]. Skin precursors/epidermal stem cells have been located within specific niches in the hair follicle and the epidermis. These cells ensure the maintenance of adult skin homeostasis and hair regeneration, but they also participate in the repair of the epidermis after injury [43].

Thus, stem cells can be obtained from many tissues with relative ease and are therefore available for research and clinical applications. Because a better understanding of their biology is fundamental for their use in clinical therapies, it is important to comprehend the niche concept.

\section{Diversity of the stem cell niche}

The term niche was first coined by Schofield in 1978, who originally hypothesized the existence of an anatomical compartment required for maintenance of stem cells [44]. Stem cell niches are proposed as physical and dynamic spaces that transmit and receive signals to govern stem cell quiescence and self-renewal [45]. This local microenvironment also protects stem cells by maintaining a low partial oxygen pressure [46]. Indeed, it has been described that hypoxia-inducible factors regulate the HSC niche [47].

Two basic types of niches have been described: stromal niches, where stem cells are not always present, and epithelial niches devoid of specialized cells [48]. Niches have been identified in diverse localizations. ESCs are derived from the inner cell mass, indicating the presence a special niche in the embryo with various factors that induce their differentiation for embryo development [49]. ESCs have garnered much attention as a source of cells for regenerative therapies due to their almost indefinite self-renewal capacity in culture and their robust differentiation into all cell types. Nonetheless, to maintain karyotypically stable ESC cultures, it is necessary to grow them on embryonic fibroblasts or some other extracellular microenvironment [50], demonstrating their niche requirement in vitro.

ASCs in the body are found in many diverse specific stem cell-niches. A structurally unique niche has been described in the bone marrow, which contains two different stem cell populations (HSCs and MSCs), both of which are tightly regulated by common signals [51]. HSCs are located principally in the red bone marrow and MSCs are found mainly in the stromal bone marrow. A stem cell niche can be found in almost every tissue. Adipose tissue represents an important stem cell source and APCs are associated with perivascular cells surrounding the blood vessels in adipose tissue and reside in hypoxic locations [52]. Satellite cells of the skeletal muscle are located along muscle fibers, between the basement membrane and the sarcolemma [28]. Whereas cardiac progenitors have been identified in the heart, the specific niche localization remains elusive [53]. However, it has been reported that the myocardium possesses interstitial structures with the architectural organization of stem cell niches that harbor cardiac progenitors [54]. The vascular system contains endothelial progenitors and pericytes located in different vasculature components that are actively involved in tissue repair, which correspond to a vascular niche present in various tissues [55]. Endodermal progenitors are less well studied and little has been reported on potential niche locations. It is known that lung contains a stem cell population that appears to reside in the intercartilage region, where there are abundant blood vessels and nerves [56]. Bronchoalveolar duct junctions have been also proposed to act as niches [57]. Hepatic progenitors in the liver can be found in the canals of Hering, where cells are slow-cycling precursors, and in the space of Disse, where cells are quiescent [58]. In the pancreas, progenitor epithelial cells are located in the pancreatic ducts [59]. The nervous system harbors a NSC population in the 
subventricular and subgranular zones [60]. A recent study has demonstrated the existence of a stem cell niche in the lateral ventricle choroid plexus [61], the main producer of cerebral spinal fluid, which secretes signals to modulate the activity of NSCs. Skin is a very wellstudied source of stem cells, and it is known that progenitor populations reside in the epidermis and hair follicles, ensuring the maintenance of adult skin homeostasis and hair regeneration [43].

Despite their different anatomical locations, it is clear that niche environments share common components: I) Stromal support cells are the major components, but cellcell adhesion molecules and secreted factors also play an important role; II) ECM proteins establish a supportive scaffold between cells; III) the vasculature is responsible for providing nutritional support, signaling and exchange between the niche and the remaining tissues; and IV) nervous system, which facilitates stem cell mobilization through neural input with different organ systems.

Niche maintenance is dependent on the complex interplay between soluble mediators, intrinsic signaling pathways and microenvironmental signals [62]. Regulation can be modulated by local signaling, by long-distance cues with hormones or by the autonomic nervous system. Indeed, it is well known that secreted factors from the bone marrow microenvironment are important for HSC maintenance, such as CXCL12, angiopoietin-1 or TGFalpha $[48,63]$. Some studies have demonstrated how the sympathetic nervous system can regulate bone marrow and mobilize HSCs [64], and how hormone signaling can promote a stem cell niche response [65]. Therefore, the precise interactions between niche components and various other factors, including the metabolic milieu, and the resident tissue environment, is important for proper stem cell function.

Notwithstanding the intrinsic capabilities of stem cell niches to self-regulate their activity through

Table 1. Diseases potentially affecting stem cell behavior. HSC: hematopoietic stem cell, MSC: mesenchymal stem cell, APC: adipose progenitor cell, SMPC: skeletal muscle progenitor cell, EP: endothelial progenitor, NSC: neural stem cell, CPC: cardiac precursor cell

\begin{tabular}{lc}
\hline Disease & Cell type affected \\
\hline Aging & HSC [137], MSC [138, 139], APCs [140], SMPC[141, 142], \\
EP [143, 144], NSC [145]. \\
Osteoporosis \\
MSC [76, 77]. \\
Cardiovascular diseases & CPC [80, 81]. \\
Obesity & APC [88, 89, 146], HSC [90], MSC [91, 147]. \\
Diabetes & HPC [92], HSC [93], EP [94]. \\
Hypercholesterolemia & MSC [101, 102], NSC [148]. \\
Glucocorticoids imbalance & MSC [107, 108]. \\
Rheumatoid arthritis & MSC [111, 149]. \\
Systemic lupus erythematosus & HSC [118, 123], MSC [123, 124]. \\
Cancer & MSC [127, 129], HSC [128]. \\
Aplastic anemia &
\end{tabular}

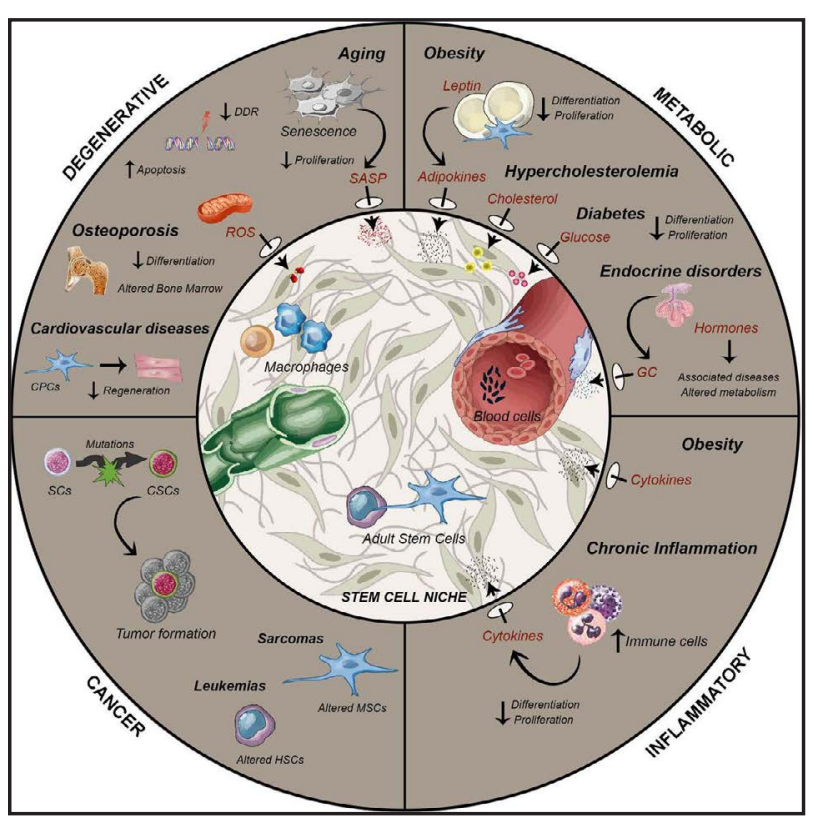

Fig. 2. Stem cell niche behavior in disease. Fig. displays the alterations to the niche triggered by different diseases, which may alter the main stem cell properties and hinder their use in cell therapies. Black arrows show molecules affecting the stem cell niche. DDR: DNA Damage Response, ROS: Reactive Oxygen Species, SASP: Senescence Associated Secretory Phenotype, GC: Glucocorticoids, SCs: Stem Cells, CSCs: Cancer Stem Cells, CPCs: Cardiac Progenitor Cells, HSC: Hematopoietic Stem Cells, MSCs: Mesenchymal Stem Cells. 
the mechanisms described above, various pathological conditions can influence the output of the niche and ultimately affect stem cell behavior, as reviewed below.

\section{Stem cell behavior in different diseases}

The stem cell niche is tightly regulated in adult tissues though the combined action of local and systemic effectors [66]. Under normal physiological conditions, stem cells maintain tissue homeostasis by responding to perturbations through proliferation and differentiation. Nevertheless, some disease states have the capacity to alter the properties of stem cells, such that their quality might be compromised, excluding their use for regenerative therapies. In the following section, we present a diverse group of diseases described to affect stem cell behavior (Table 1), and hence must be considered before their use in cell therapy. We have grouped these disorders into four classes: degenerative, cardiovascular, metabolic, and inflammatory disease (Fig. 2).

\section{Aging and degenerative diseases}

The concept of degeneration makes reference to a process whereby tissue deteriorates and loses its functional ability due to genetic or environmental factors. Some degenerative diseases can alter stem cell properties, such as aging or osteoporosis.

Aging is the most common studied health condition that directly affects the properties of stem cells [67]. Aging is a complex process that represents the accumulation of changes over time in an organism. Although not a degenerative disease per se, the continuous cell and tissue changes throughout life make it similar to degenerative processes. The life-long persistence of stem cells makes them vulnerable to the accumulation of cellular damage, which can lead to senescence, loss of regenerative function or even to cell death [67]. Many tissues show a decrease in the ASC population with age, as well as proliferative dysregulation and a decline in functional capacity [68]. This effect clearly reduces the effectiveness of cell repair and regeneration in aged organisms. Aging also affects stem cell behavior through modifications in niche compartments [69], causing the loss of acellular components and alterations in molecular factors [70].

It is generally accepted that the accumulation of toxic metabolites, including reactive oxygen species (ROS) [71], can lead to the progressive damage of DNA and other macromolecules. Protein homeostasis, which includes synthesis and turnover of the proteome, is equally important to assure stem cell function and aging is one of the main risk factors associated with protein quality control due to failures in autophagy-lysosomal and ubiquitin-proteasome systems [72]. Furthermore, mitochondrial dysfunction is causatively linked to some phenotypes of aging, and can result from the accumulation of mutations in mitochondrial DNA [73].

Collectively, these processes promote the gradual loss of stem cell functionality and lead to a depletion of the stem cell pool in aged individuals. In addition, they have also been associated with a decline in stem cell regenerative capacity. The principal stem cell populations known to be affected by aging with regard to their cell abundance, behavior and impact are HSCs, MSCs, intestinal stem cells, satellite cells of the skeletal muscle, NSCs, skin stem cells and germ-line stem cells [74].

Osteoporosis is an age-related disease characterized by a reduction in bone mass [75]. It has been shown that MSCs from osteoporotic patients present a deficiency in osteogenic differentiation [76]. Moreover, MSCs from patients with osteoarthritis, which is associated with degenerative changes both in bone and cartilage, present reduced chondrogenic and adipogenic activity [77]. These studies confirm that a correct homeostatic maintenance of tissues is required to prevent alterations within MSC populations.

Cardiovascular diseases are a group of pathological disorders affecting the cardiovascular system. While many factors can be involved in the etiology of the disease, such as atherosclerosis, hypertension, stroke and coronary artery disease, the general consequence 
is blood vessel dysfunction or heart failure [78]. Heart failure occurs when the heart is unable to pump sufficient blood to the body and it is associated with a progressive and considerable loss of cardiomyocytes [79]. Loss of competent CPCs in chronic ischemic cardiomyopathy may underlie terminal heart failure [80]. Interestingly, an age-related cardiac defect has been reported, with CPCs undergoing senescent-like changes that impair their regenerative capacity [81]. Additionally, diabetes leads to a decompensated myopathy through enhanced oxidative stress, in which oxygen toxicity may alter CPC function ultimately resulting in growth defects and myocyte malformation [82]. All these effects promote stem cell death and impair heart regeneration, and so clearly they would be of little use in autologous therapy. It is important to remember that the behavior of the heart is likely no different to that of other self-renewing organs and its tissue-specific stem cells will be equally affected by the diverse negative alterations. However, the potential self-renewing ability of the heart remains controversial and it is currently thought that dividing myocytes rather than CPCs are the cells involved in tissue repair.

\section{Metabolic disorders}

Several metabolic syndromes cause alterations to the stem cell niche, including the presence or absence of specific metabolites. The most common underlying pathologies include obesity, diabetes, hypercholesterolemia and endocrine disorders.

Obesity is a metabolic disease conditioned by environmental and genetic factors [83]. Obesity is associated with a pro-inflammatory response in a wide variety of tissues, contributing to tissue inflammation and metabolic disease [84]. The inflammatory response triggers an increase in circulating cytokines, leukocyte recruitment and their activation, and the generation of a reparative response. Indeed, obesity is associated with a chronic lowgrade inflammation characterized by the continuous activation of the immune system. The negative effects of obesity on stem cells described are numerous. Subcutaneous adipose tissue from obese patients has a diminished reservoir of functionally active stem cells [85]. Moreover, metabolism and maturation of APCs are arrested in an obese environment [17], and their ability to migrate or invade a tissue is impaired [86, 87]. Mechanistically, obesity causes a short circuit in the stemness gene network [88], promoting an imbalance in metabolism and a reduction in stemness properties [89]. These alterations have been described mainly in the adipose tissue reservoir because of changes to the adipose tissue niche. Nevertheless, some studies have examined the negative effect of obesity for the bone marrow niche [90]. Chronic low-grade inflammation associated with obesity is a stressor for HSCs and MSCs resident in the bone marrow due to the continuous response to cytokine inflammation. In turn, inflammation causes alterations in the microenvironment with implications for cell production [90]. This therefore implies that obesity impedes proper functioning of the immune system through an impairment in the bone marrow niche [91]. Thus, obesity has a negative impact on various stem cell populations due to metabolic imbalance and associated inflammation, both affecting stem cell reservoirs.

Diabetes is characterized by metabolic abnormalities in carbohydrate and lipid metabolism and altered immune function. Cramer et al. investigated the effect of prolonged hyperglycemia on MSC properties using APCs from non-diabetic (nAPC) and diabetic (dAPC) donors, observing an impaired function of dAPCs for glucose metabolism, cell replication, apoptosis, and differentiation potential [92]. Additionally, it has been described that diabetes impairs HSC mobilization via altered perivascular neural and mesenchymal cell function in bone marrow [93], and also weakens vascular repair by marrow-derived endothelial progenitor cells [94]. Nevertheless, it has been also described that MSCs from patients with newly diagnosed type 1 diabetes mellitus, also known as autoimmune diabetes and characterized by $\beta$-cell loss, exhibit preserved in vitro and in vivo immunomodulatory properties $[95,96]$. Compared with those from healthy donors, MSCs from patients showed no differences in terms of morphology, gene expression, immunosuppressive activity and migratory capacity, and so they could be used for autologous systemic therapy.

\section{KARGER}


Hypercholesterolemia, also known as dyslipidemia, is characterized by the presence of high levels of cholesterol in the blood. It typically results from a combination of environmental (diet, obesity) and genetic factors. It has recently been described that hypercholesterolemia may cause aging of HSCs [97]. Tie et al. showed that high levels of dietary cholesterol leads to the accumulation of oxidized low-density lipoprotein in a variety of cells and tissues that promotes phenotypic changes characteristic of aging, including altered ROS metabolism, loss of quiescence and a decreased proliferation capacity [97]. Furthermore, it has been shown that hypercholesterolemia induces a pathologic state in HSC populations [98], favoring the development of pro-inflammatory myeloid cells that aggravate the development of atherosclerosis.

Table 2. Endocrine organs, hormones and their potential effects on stem cell populations

Endocrine organ and hormones

Hypothalamus: Thyrotropin-releasing hormone, dopamine, growth hormone-releasing hormone, somatostatin, gonadotropin-releasing hormone, corticotropin-releasing hormone and vasopressin.

Pineal gland: Melatonin.

Pituitary gland: Growth hormone, thyroidstimulating hormone, adrenocorticotropic hormone, beta-endorphin, follicle-stimulating hormone, luteinizing hormone, prolactin, melanocyte-stimulating hormone, oxytocin and vasopressin.

Thyroid: Triiodothyronine, thyroxine and calcitonin.

Parathyroid: Parathyroid hormone.

Adipose tissue: Leptin*.

Digestive System: Gastrin, secretin, cholecystokinin, gastric inhibitory peptide and motilin.

Liver: Insulin-like growth factor, angiotensinogen, angiotensin and thrombopoietin. Pancreas: Insulin, glucagon, somatostatin and pancreatic polypeptide

Kidney: Renin, erythropoietin, calcitriol and thrombopoietin.

Adrenal gland: Glucocorticoids, mineralocorticoids and androgen. adrenaline, noradrenaline and dopamine.

Sexual organs: Androgens, estradiol, inhibin, progesterone, androstenedione and estrogens.
Potential stem cell effect

Hypothalamic hormones stimulate or inhibit the secretion of pituitary hormones and control body temperature, hunger, thirst, fatigue, sleep, and circadian rhythms. Their altered quantity or quality leads to general body disturbance.

Melatonin secretion progressively declines with age, but is also strongly reduced in Alzheimer disease, neurological and stressful conditions, pain, cardiovascular disease, some types of cancer and in endocrine and metabolic disorders [150]. Melatonin has been recently described to protect cells from ROS [151].

Among the pituitary hormones, ACTH excess induces an overproduction of cortisol (Glucocorticoid*). However, all hormones are related to metabolism and can affect the stem cell niche.

Hyper- and Hypothyroidism leads to dysregulated metabolism.

Hyper- and hypoparathyroidism are characterized by alterations in blood calcium levels and bone metabolism, so

could have an effect on bone-marrow stem cells.

Alterations in leptin levels induce body weight changes and have a well-described negative effect on adipose stem cell populations.

Changes in gastrointestinal hormones by digestive disorders are related to metabolic diseases that could also alter some stem cell niches.

Hepatic and pancreatic hormones are implicated in different metabolic pathways. Altered hormonal levels in these organs are related to diabetic processes, weight loss and obesity, and consequently the adipose stem cell niche

Altered calcitriol levels affect vitamin D receptor functions that are essential for normal stem cell function [152]. Others are important in bone marrow regulation

Adrenal hormones are implicated in metabolism, and so have important effects on the stem cell niche*.

It has been shown that sexual dimorphism influences stem cell functions throughout the body. Recent studies reported the effect of some of these hormones on stem cells properties [154] [155]. 
Endocrine disorders. The endocrine system refers to a group of glands that produce and secrete hormones into the blood to regulate a variety of physiological processes. It is considered an information signaling system via molecular signals that act in different body locations. Many organs have secondary endocrine functions. The major endocrine glands or organs, their hormones and their potential or described effects on stem cell populations are listed in Table 2. Different hormonal disorders can cause alterations in the stem cell environment, among which is the well-described effects produced by changes to glucocorticoid levels.

Glucocorticoids (GCs) are steroid hormones that seem to affect almost every tissue and organsysteminthebody. Clinically, theyareusedas anti-inflammatory andimmunosuppressive drugs for a variety of diseases such as inflammation, cancer and autoimmune disorders [99]. GC levels can be elevated in patients due to treatment with supraphysiological levels or by generation through natural excess (e.g., in Cushing's disease). Irrespective of the reason for their elevated levels, GCs can impact on stem cell properties especially via their effects on metabolism [100]. Accordingly, it has been described that GCs have inhibitory effects on bone marrow stromal stem cell proliferation and osteoblastic differentiation, resulting in decreased bone formation [101]. Indeed, GCs appear to selectively and negatively impact on cells and tissues that arise from bone marrow-derived stem cells [102].

\section{Inflammatory diseases}

The inflammatory response is a primary defense mechanism that occurs immediately following injury or infection and is necessary to restore tissue function [103]. A persistent stimulus leads to chronic inflammation, with a dysregulation between destructive inflammatory and excessive healing responses seen in diseases such as arthritis, atherosclerosis and asthma [104]. Chronic inflammation is caused by a variety of factors and can predispose an individual to obesity, diabetes or cancer [105]. Some pathologies have been described whose inflammatory responses are related to the negative effects on ASC populations. As mentioned earlier, obesity and its related inflammatory state promote altered stem cell states. Other inflammatory diseases with direct effects on stem cells are being actively investigated.

Rheumatoid arthritis is a systemic autoimmune disease with an unknown etiology that is characterized by chronic inflammation of the joints and an imbalance in cell and cytokine profiles [106]. Abnormalities both in hematopoietic progenitor cells and bone marrow stromal cells have been described [107], and patients with active rheumatoid arthritis present a low frequency and accelerated apoptosis of bone marrow $\mathrm{CD} 34^{+}$cells, defective clonogenic potential of marrow progenitor cells, and impaired hematopoiesis. Significant changes occur with disease progression including alterations in self-renewal and differentiation of bone marrow MSCs, which changes the composition of the microenvironment [108]. Regarding their use in therapies, cell abnormalities might impact on the harvesting and engraftment potential of stem cells in these patients.

Systemic lupus erythematosus (SLE) is an autoimmune disease involving several vital organs and is characterized by an autoreactive immune system that attacks the patient's own tissues [109]. It has been shown that MSCs from SLE patients have an altered morphological and phenotypical state, showing early signs of senescence. Cells also present an altered telomerase activity and have reduced proliferative capacity $[110,111]$.

In conclusion, inflammatory diseases can lead to the increase in levels of immune cells and cytokines that can affect stem cell biology through alterations to the niche.

\section{Altered stem cell behavior in cancer}

Stem cell populations may be altered by genetic or environmental factors and can be related to the development of cancer. Cancer involves abnormal cell growth and an acquired potential to invade or spread to remote tissues. Cell transformation is due to a progressive accumulation of acquired mutations in normal cells. Two hypotheses currently exist for the origin of cancer [112]. One proposes that any cell in the body can undergo changes and 
become a cancer cell, and the other postulates that ASCs initiate the carcinogenic process. As the microenvironment has a critical role in regulating stem cell function, alterations to the niche can also play a role in the development of cancer $[113,114]$. Because the balance between the states of stemness and differentiation depend on conditions in the niche, alterations in the niche at the signaling or structural levels could lead to the development of certain cancers [115].

The cancer stem cell (CSC) hypothesis proposes that tumors appear to rely on a pool of CSCs that are phenotypically similar to normal stem cells since they share an ability to proliferate, self-renew and generate differentiated cells. However, CSCs lose the mechanisms that regulate proliferation and differentiation, through mutation in important pathways such us Wtn, Notch or Hedgehog [116], resulting in uncontrolled growth and incomplete differentiation of tumor cells [117]. While the target cell is unknown in most cancer types, certain cancers have mutations in a stem cell, leading to the development of cancer as discussed below.

Leukemia comprises a group of hematological disorders characterized by abnormal proliferation of white blood cells. Chronic exposure to intrinsic and extrinsic stress can cause DNA damage to stem cell populations, leading to mutations and resulting in malignant transformation [118]. Leukemia is the result of deregulation of normal HSC development by genetic mutations that produce a population known as leukemic stem cells (LSCs). Several types of leukemia have been identified, including acute lymphoblastic leukemia (ALL), acute myeloid leukemia (AML), chronic lymphoblastic leukemia (CLL) and chronic myeloid leukemia (CML). The existence of LSCs was first described in AML [119] and many studies have identified mutations in different genes [reviewed in [120], and many other genes have been described in CML [121]. The existence of LSCs derived by malignant transformation of stem cells for is less clear for ALL, and instead it appears to be caused by a variety of mutated committed progenitors [122].

Sarcomas are a rare and diverse group of tumors that derive from mesenchymal tissues. There is evidence to suggest that MSCs might be tumor-initiating cells, capable of initiating sarcomagenesis [123]. There are also reports showing that sarcomas represent good examples of the CSC model; however, it has yet to be shown whether MSCs are the cell of origin. An important model for cancers originating in progenitor-type cells is Ewing Sarcoma [124], which is a biologically aggressive malignancy of bone and soft tissue initiated by a chromosomal translocation. Overexpression of the fusion gene resulting from this translocation in mesenchymal progenitor cells can in part phenocopy the sarcoma, whereas its gene silencing in tumor cells results in a gene signature resembling mesenchymal progenitor cells [124].

Breast cancer constitutes the first human cancer for which a putative CSC has been isolated, although other candidate CSCs have been identified in many other malignancies. Some reports have related the existence of mammary stem cells existence and their transformation as a model of carcinogenesis in breast cancer [reviewed in [125]. It has been suggested that human breast tumors contain a cell pool of CSCs with tumorigenic properties [126]. Nevertheless, whether these pathologies originate from altered normal stem cells or not, tumor growth apparently depends on a small population of stem-like cells.

In contrast to the general unchecked proliferation of malignant cells in cancer, some diseases are categorized by a decrease (or an absence) in cell number. Aplastic anemia is an unusual disease in which the bone marrow is injured and there is a break in the production of new blood cells due to damage to the stem cell population [127]. It can be caused by several factors, among which are exposure to chemicals, drugs or radiation, immune disease or unknown causes, which can affect both HSC and MSC populations. Aplastic anemia was originally suggested to be a primary HSC deficiency or a secondary HSC defect due to an abnormal balance between cellular death and differentiation [128]. However, MSCs as marrow microenvironment cells may also play an important role in the development of the disease by causing an imbalance in immune regulation and aggravating bone marrow failure [129]. 


\section{Conclusion}

Stem cell therapy has the potential to be an important resource to treat many diseases that currently cannot be cured by traditional pharmacological therapy. The therapeutic potential of stem cells has profoundly changed the landscape of medical research, generating a new field of regenerative medicine. However, many studies have demonstrated the potential disadvantages of using some stem cells, which depend in part on the physiological state of their source of origin.

The degeneration of tissue-specific stem cell regenerative potential is a hallmark of aging, but may also be associated with diverse diseases. Here, we have reviewed the influence of systemic factors present due to different pathologies and their effect on diverse progenitor cells, and how disease could alter the stem cell hallmarks (Fig. 3). We have found data about altered genomic instability [130], telomere attrition [89, 131], epigenetic alterations [132], loss of proteostasis and deregulated

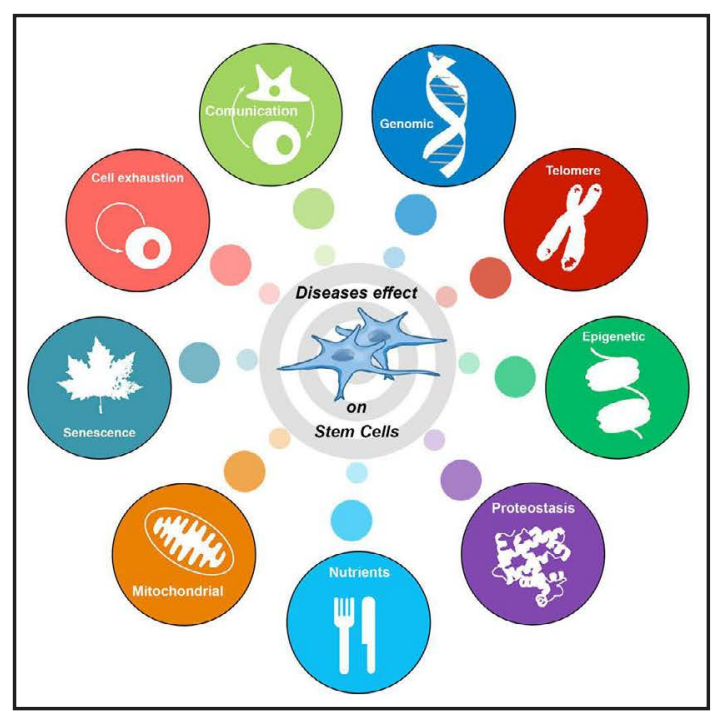

Fig. 3. Altered hallmarks on stem cells. The illustration encompasses the altered hallmarks on stem cells by different diseases. Some diseases could promote genomic instability, telomere attrition, epigenetic alterations, loss of proteostasis, deregulated nutrients, mitochondrial dysfunction, cellular senescence, stem cell exhaustion and altered cell communication. nutrients [88], mitochondrial dysfunction $[133,134]$, cellular senescence and stem cell exhaustion [85] and altered cell communication [135]. Along this line, different studies using heterochronic parabiosis experiments elegantly demonstrated that environmental factors influence stem cell functions [136]; exposure of stem cells to systemic factors from young mice increased their proliferative capacity. Pairing two animals in parabiosis proves that circulatory factors from one animal can affect the other. Given the remarkable ability of stem cells to respond to different stimuli, it is not surprising that different diseases may impact stem cells and their niches.

It is clearly important to know the quality of the stem cell source for its use in regenerative medicine and it is especially relevant for autologous stem cell transplantation regimens to consider the patient's disease history. Also important is the health history of the donors who participate in different stem cell therapies. Further studies are needed to ensure the quality and safety of large-scale expansion of patient ASCs prior to their potential use in clinical trials.

\section{Abbreviations}

ALL (acute lymphoblastic leukemia); AML (acute myeloid leukemia); APC (adipose progenitor cell); ASC (adult stem cell); CLL (chronic lymphoblastic leukemia); CML (chronic myeloid leukemia); CPC (cardiac precursor cell); CSC (cancer stem cell); dAPC (diabetic adipose progenitor cell); ECM (extracellular matrix); ESC (embryonic stem cell); GC (glucocorticoid); HSC (hematopoietic stem cell); LSC (leukemic stem cell); MHC (major histocompatibility complex); MSC (mesenchymal stem cell); nAPC (non-diabetic adipose progenitor cell); NSC (neural stem cell); ROS (reactive oxygen species); SLE (systemic lupus erythematosus). 


\section{Cellular Physiology Cell Physiol Biochem 2018;46:1999-2016 \begin{tabular}{l|l} 
and Biochemistry Published 10.1159/000489440 & $\begin{array}{l}\text { D) } 2018 \text { The Author(s). Published by S. Karger AG, Basel } \\
\text { www.karger.com/cpb }\end{array}$
\end{tabular}}

Pérez et al.: Disturbed Stem Cell Properties

\section{Acknowledgements}

This study was supported by grant from the Spanish Ministry of Science and Innovation (SAF 2015-67911-R) to BGG. BdL is supported by FPU fellowships from the Spanish Ministry of Science and Innovation. We would like to thank Dr Kenneth McCreath for critically reviewing the manuscript.

LMP wrote the manuscript. BdL and BGG revised the manuscript. All authors read and approved the final manuscript.

\section{Disclosure Statement}

The authors declare to have no conflict of interests.

\section{References}

1 O'Brien LE, Bilder D: Beyond the niche: tissue-level coordination of stem cell dynamics. Annu Rev Cell Dev Biol 2013;29:107-136.

-2 Scadden DT: The stem-cell niche as an entity of action. Nature 2006;441:1075-1079.

3 Chagastelles PC, Nardi NB: Biology of stem cells: an overview. Kidney Int Suppl (2011) 2011;1:63-67.

4 Mountford JC: Human embryonic stem cells: origins, characteristics and potential for regenerative therapy. Transfus Med 2008;18:1-12.

5 Caplan AI, Bruder SP: Mesenchymal stem cells: building blocks for molecular medicine in the 21st century. Trends Mol Med 2001;7:259-264.

-6 Evans MJ, Kaufman MH: Establishment in culture of pluripotential cells from mouse embryos. Nature 1981;292:154-156.

7 Pittenger MF, Mackay AM, Beck SC, Jaiswal RK, Douglas R, Mosca JD, Moorman MA, Simonetti DW, Craig S, Marshak DR: Multilineage potential of adult human mesenchymal stem cells. Science 1999;284:143-147.

8 Weissman IL: Translating stem and progenitor cell biology to the clinic: barriers and opportunities. Science 2000;287:1442-1446.

-9 Spangrude GJ, Heimfeld S, Weissman IL: Purification and characterization of mouse hematopoietic stem cells. Science 1988;241:58-62.

10 Amos TA, Gordon MY: Sources of human hematopoietic stem cells for transplantation--a review. Cell Transplant 1995;4:547-569.

11 Kondo M, Wagers AJ, Manz MG, Prohaska SS, Scherer DC, Beilhack GF, Shizuru JA, Weissman IL: Biology of hematopoietic stem cells and progenitors: implications for clinical application. Annu Rev Immunol 2003;21:759-806.

-12 Majeti R, Park CY, Weissman IL: Identification of a hierarchy of multipotent hematopoietic progenitors in human cord blood. Cell Stem Cell 2007;1:635-645.

-13 Friedenstein AJ, Gorskaja JF, Kulagina NN: Fibroblast precursors in normal and irradiated mouse hematopoietic organs. Exp Hematol 1976;4:267-274.

14 Oh M, Nor JE: The Perivascular Niche and Self-Renewal of Stem Cells. Front Physiol 2015;6:367.

15 Chong PP, Selvaratnam L, Abbas AA, Kamarul T: Human peripheral blood derived mesenchymal stem cells demonstrate similar characteristics and chondrogenic differentiation potential to bone marrow derived mesenchymal stem cells. J Orthop Res 2012;30:634-642.

-16 Fraser JK, Wulur I, Alfonso Z, Hedrick MH: Fat tissue: an underappreciated source of stem cells for biotechnology. Trends Biotechnol 2006;24:150-154.

17 Perez LM, Bernal A, San Martin N, Lorenzo M, Fernandez-Veledo S, Galvez BG: Metabolic rescue of obese adipose-derived stem cells by Lin28/Let7 pathway. Diabetes 2013;62:2368-2379.

18 Griffiths MJ, Bonnet D, Janes SM: Stem cells of the alveolar epithelium. Lancet 2005;366:249-260.

19 Bernal A, Fernandez M, Perez LM, San Martin N, Galvez BG: Method for obtaining committed adult mesenchymal precursors from skin and lung tissue. PLoS One 2012;7:e53215. 


\section{Cellular Physiology Cell Physiol Biochem 2018;46:1999-2016 \begin{tabular}{l|l} 
and Biochemistry Published 10.1159/000489440 & $\begin{array}{l}\text { (c) 2018 The Author(s). Published by S. Karger AG, Basel } \\
\text { www.karger.com/cpb }\end{array}$
\end{tabular}}

Pérez et al.: Disturbed Stem Cell Properties

20 Hass R, Kasper C, Bohm S, Jacobs R: Different populations and sources of human mesenchymal stem cells (MSC): A comparison of adult and neonatal tissue-derived MSC. Cell Commun Signal 2011;9:12.

-21 Zachar L, Bacenkova D, Rosocha J: Activation, homing, and role of the mesenchymal stem cells in the inflammatory environment. J Inflamm Res 2016;9:231-240.

-22 Ryan JM, Barry FP, Murphy JM, Mahon BP: Mesenchymal stem cells avoid allogeneic rejection. J Inflamm (Lond) 2005;2:8.

-23 Seaberg RM, van der Kooy D: Stem and progenitor cells: the premature desertion of rigorous definitions. Trends Neurosci 2003;26:125-131.

-24 Potten CS, Loeffler M: Stem cells: attributes, cycles, spirals, pitfalls and uncertainties. Lessons for and from the crypt. Development 1990;110:1001-1020.

25 Klimczak A, Kozlowska U: Mesenchymal Stromal Cells and Tissue-Specific Progenitor Cells: Their Role in Tissue Homeostasis. Stem Cells Int 2016;2016:4285215.

-26 Hausman DB, Park HJ, Hausman GJ: Isolation and culture of preadipocytes from rodent white adipose tissue. Methods Mol Biol 2008;456:201-219.

27 Peault B, Rudnicki M, Torrente Y, Cossu G, Tremblay JP, Partridge T, Gussoni E, Kunkel LM, Huard J: Stem and progenitor cells in skeletal muscle development, maintenance, and therapy. Mol Ther 2007;15:867877.

28 Yin H, Price F, Rudnicki MA: Satellite cells and the muscle stem cell niche. Physiol Rev 2013;93:23-67.

29 Beltrami AP, Barlucchi L, Torella D, Baker M, Limana F, Chimenti S, Kasahara H, Rota M, Musso E, Urbanek K, Leri A, Kajstura J, Nadal-Ginard B, Anversa P: Adult cardiac stem cells are multipotent and support myocardial regeneration. Cell 2003;114:763-776.

-30 Galvez BG, Sampaolesi M, Barbuti A, Crespi A, Covarello D, Brunelli S, Dellavalle A, Crippa S, Balconi G, Cuccovillo I, Molla F, Staszewsky L, Latini R, Difrancesco D, Cossu G: Cardiac mesoangioblasts are committed, self-renewable progenitors, associated with small vessels of juvenile mouse ventricle. Cell Death Differ 2008;15:1417-1428.

-31 Kovacic JC, Boehm M: Resident vascular progenitor cells: an emerging role for non-terminally differentiated vessel-resident cells in vascular biology. Stem Cell Res 2009;2:2-15.

-32 Asahara T, Murohara T, Sullivan A, Silver M, van der Zee R, Li T, Witzenbichler B, Schatteman G, Isner JM: Isolation of putative progenitor endothelial cells for angiogenesis. Science 1997;275:964-967.

33 Mills SJ, Cowin AJ, Kaur P: Pericytes, mesenchymal stem cells and the wound healing process. Cells 2013;2:621-634.

34 Cossu G, Bianco P: Mesoangioblasts--vascular progenitors for extravascular mesodermal tissues. Curr Opin Genet Dev 2003;13:537-542.

-35 McQualter JL, Yuen K, Williams B, Bertoncello I: Evidence of an epithelial stem/progenitor cell hierarchy in the adult mouse lung. Proc Natl Acad Sci U S A 2010;107:1414-1419.

-36 Noguchi H: Pancreatic stem/progenitor cells for the treatment of diabetes. Rev Diabet Stud 2010;7:105111.

37 Ku HT: Minireview: pancreatic progenitor cells--recent studies. Endocrinology 2008;149:4312-4316.

-38 Kopp JL, Grompe M, Sander M: Stem cells versus plasticity in liver and pancreas regeneration. Nat Cell Biol 2016;18:238-245.

39 Cardinale V, Wang Y, Carpino G, Cui CB, Gatto M, Rossi M, Berloco PB, Cantafora A, Wauthier E, Furth ME, Inverardi L, Dominguez-Bendala J, Ricordi C, Gerber D, Gaudio E, Alvaro D, Reid L: Multipotent stem/ progenitor cells in human biliary tree give rise to hepatocytes, cholangiocytes, and pancreatic islets. Hepatology 2011;54:2159-2172.

40 Kornblum HI: Introduction to neural stem cells. Stroke 2007;38:810-816.

41 Clarke DL, Johansson CB, Wilbertz J, Veress B, Nilsson E, Karlstrom H, Lendahl U, Frisen J: Generalized potential of adult neural stem cells. Science 2000;288:1660-1663.

42 Cavallucci V, Fidaleo M, Pani G: Neural Stem Cells and Nutrients: Poised Between Quiescence and Exhaustion. Trends Endocrinol Metab 2016;10.1016/j.tem.2016.06.007

43 Blanpain C, Fuchs E: Epidermal stem cells of the skin. Annu Rev Cell Dev Biol 2006;22:339-373.

44 Schofield R: The relationship between the spleen colony-forming cell and the haemopoietic stem cell. Blood Cells 1978;4:7-25.

45 Jones DL, Wagers AJ: No place like home: anatomy and function of the stem cell niche. Nat Rev Mol Cell Biol 2008;9:11-21. 


\section{Cellular Physiology Cell Physiol Biochem 2018;46:1999-2016 \begin{tabular}{l|l} 
DOI: 10.1159/000489440 & Ond 2018 The Author(s). Published by S. Karger AG, Basel \\
www.karger.com/cpb
\end{tabular}}

Pérez et al.: Disturbed Stem Cell Properties

46 Dalloul A: Hypoxia and visualization of the stem cell niche. Methods Mol Biol 2013;1035:199-205.

47 Morikawa T, Takubo K: Hypoxia regulates the hematopoietic stem cell niche. Pflugers Arch 2015;10.1007/ s00424-015-1743-z

48 Morrison SJ, Spradling AC: Stem cells and niches: mechanisms that promote stem cell maintenance throughout life. Cell 2008;132:598-611.

49 Bendall SC, Stewart MH, Bhatia M: Human embryonic stem cells: lessons from stem cell niches in vivo. Regen Med 2008;3:365-376.

50 Dickinson LE, Kusuma S, Gerecht S: Reconstructing the differentiation niche of embryonic stem cells using biomaterials. Macromol Biosci 2011;11:36-49.

51 Mendez-Ferrer S, Michurina TV, Ferraro F, Mazloom AR, Macarthur BD, Lira SA, Scadden DT, Ma'ayan A, Enikolopov GN, Frenette PS: Mesenchymal and haematopoietic stem cells form a unique bone marrow niche. Nature 2010;466:829-834.

-52 Kaewsuwan S, Song SY, Kim JH, Sung JH: Mimicking the functional niche of adipose-derived stem cells for regenerative medicine. Expert Opin Biol Ther 2012;12:1575-1588.

53 Leri A, Rota M, Hosoda T, Goichberg P, Anversa P: Cardiac stem cell niches. Stem Cell Res 2014;13:631-646.

54 Urbanek K, Cesselli D, Rota M, Nascimbene A, De Angelis A, Hosoda T, Bearzi C, Boni A, Bolli R, Kajstura J, Anversa P, Leri A: Stem cell niches in the adult mouse heart. Proc Natl Acad Sci U S A 2006;103:9226-9231.

55 Geevarghese A, Herman IM: Pericyte-endothelial crosstalk: implications and opportunities for advanced cellular therapies. Transl Res 2014;163:296-306.

56 Banerjee ER: Looking for the elusive lung stem cell niche. Transl Respir Med 2014;2:7.

-57 Giangreco A, Reynolds SD, Stripp BR: Terminal bronchioles harbor a unique airway stem cell population that localizes to the bronchoalveolar duct junction. Am J Pathol 2002;161:173-182.

58 Kordes C, Haussinger D: Hepatic stem cell niches. J Clin Invest 2013;123:1874-1880.

59 Zulewski H, Abraham EJ, Gerlach MJ, Daniel PB, Moritz W, Muller B, Vallejo M, Thomas MK, Habener JF: Multipotential nestin-positive stem cells isolated from adult pancreatic islets differentiate ex vivo into pancreatic endocrine, exocrine, and hepatic phenotypes. Diabetes 2001;50:521-533.

60 Doetsch F, Caille I, Lim DA, Garcia-Verdugo JM, Alvarez-Buylla A: Subventricular zone astrocytes are neural stem cells in the adult mammalian brain. Cell 1999;97:703-716.

61 Silva-Vargas V, Maldonado-Soto AR, Mizrak D, Codega P, Doetsch F: Age-Dependent Niche Signals from the Choroid Plexus Regulate Adult Neural Stem Cells. Cell Stem Cell 2016;19:643-652.

62 Hoffman CM, Calvi LM: Minireview: complexity of hematopoietic stem cell regulation in the bone marrow microenvironment. Mol Endocrinol 2014;28:1592-1601.

63 Mendelson A, Frenette PS: Hematopoietic stem cell niche maintenance during homeostasis and regeneration. Nat Med 2014;20:833-846.

64 Asada N, Katayama Y, Sato M, Minagawa K, Wakahashi K, Kawano H, Kawano Y, Sada A, Ikeda K, Matsui T, Tanimoto M: Matrix-embedded osteocytes regulate mobilization of hematopoietic stem/progenitor cells. Cell Stem Cell 2013;12:737-747.

-65 Gancz D, Lengil T, Gilboa L: Coordinated regulation of niche and stem cell precursors by hormonal signaling. PLoS Biol 2011;9:e1001202.

66 Rojas-Rios P, Gonzalez-Reyes A: Concise review: The plasticity of stem cell niches: a general property behind tissue homeostasis and repair. Stem Cells 2014;32:852-859.

67 Yun MH: Changes in Regenerative Capacity through Lifespan. Int J Mol Sci 2015;16:25392-25432.

68 Oh J, Lee YD, Wagers AJ: Stem cell aging: mechanisms, regulators and therapeutic opportunities. Nat Med 2014;20:870-880.

69 Ferraro F, Celso CL, Scadden D: Adult stem cels and their niches. Adv Exp Med Biol 2010;695:155-168.

70 Gattazzo F, Urciuolo A, Bonaldo P: Extracellular matrix: a dynamic microenvironment for stem cell niche. Biochim Biophys Acta 2014;1840:2506-2519.

71 Yang SR, Park JR, Kang KS: Reactive Oxygen Species in Mesenchymal Stem Cell Aging: Implication to Lung Diseases. Oxid Med Cell Longev 2015;2015:486263.

-72 Tomaru U, Takahashi S, Ishizu A, Miyatake Y, Gohda A, Suzuki S, Ono A, Ohara J, Baba T, Murata S, Tanaka $\mathrm{K}$, Kasahara M: Decreased proteasomal activity causes age-related phenotypes and promotes the development of metabolic abnormalities. Am J Pathol 2012;180:963-972.

73 Bratic A, Larsson NG: The role of mitochondria in aging. J Clin Invest 2013;123:951-957. 


\section{Cellular Physiology Cell Physiol Biochem 2018;46:1999-2016

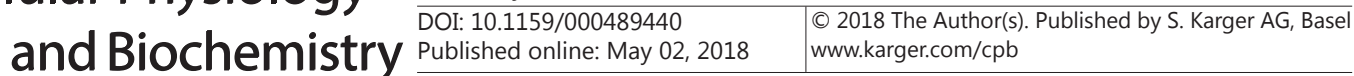

Pérez et al.: Disturbed Stem Cell Properties

74 Schultz MB, Sinclair DA: When stem cells grow old: phenotypes and mechanisms of stem cell aging. Development 2016;143:3-14.

75 Manolagas SC, Jilka RL: Bone marrow, cytokines, and bone remodeling. Emerging insights into the pathophysiology of osteoporosis. N Engl J Med 1995;332:305-311.

-76 Rodriguez JP, Garat S, Gajardo H, Pino AM, Seitz G: Abnormal osteogenesis in osteoporotic patients is reflected by altered mesenchymal stem cells dynamics. J Cell Biochem 1999;75:414-423.

-77 Murphy JM, Dixon K, Beck S, Fabian D, Feldman A, Barry F: Reduced chondrogenic and adipogenic activity of mesenchymal stem cells from patients with advanced osteoarthritis. Arthritis Rheum 2002;46:704-713.

78 Krum H, Abraham WT: Heart failure. Lancet 2009;373:941-955.

-79 Beltrami CA, Finato N, Rocco M, Feruglio GA, Puricelli C, Cigola E, Quaini F, Sonnenblick EH, Olivetti G, Anversa P: Structural basis of end-stage failure in ischemic cardiomyopathy in humans. Circulation 1994;89:151-163.

80 Galvez BG, Covarello D, Tolorenzi R, Brunelli S, Dellavalle A, Crippa S, Mohammed SA, Scialla L, Cuccovillo I, Molla F, Staszewsky L, Maisano F, Sampaolesi M, Latini R, Cossu G: Human cardiac mesoangioblasts isolated from hypertrophic cardiomyopathies are greatly reduced in proliferation and differentiation potency. Cardiovasc Res 2009;83:707-716.

81 Vasa M, Fichtlscherer S, Aicher A, Adler K, Urbich C, Martin H, Zeiher AM, Dimmeler S: Number and migratory activity of circulating endothelial progenitor cells inversely correlate with risk factors for coronary artery disease. Circ Res 2001;89:E1-7.

-82 Rota M, LeCapitaine N, Hosoda T, Boni A, De Angelis A, Padin-Iruegas ME, Esposito G, Vitale S, Urbanek K, Casarsa C, Giorgio M, Luscher TF, Pelicci PG, Anversa P, Leri A, Kajstura J: Diabetes promotes cardiac stem cell aging and heart failure, which are prevented by deletion of the p66shc gene. Circ Res 2006;99:42-52.

83 Achike FI, To NH, Wang H, Kwan CY: Obesity, metabolic syndrome, adipocytes and vascular function: A holistic viewpoint. Clin Exp Pharmacol Physiol 2011;38:1-10.

84 Lumeng CN, Saltiel AR: Inflammatory links between obesity and metabolic disease. J Clin Invest 2011;121:2111-2117.

85 Onate B, Vilahur G, Ferrer-Lorente R, Ybarra J, Diez-Caballero A, Ballesta-Lopez C, Moscatiello F, Herrero J, Badimon L: The subcutaneous adipose tissue reservoir of functionally active stem cells is reduced in obese patients. FASEB J 2012;26:4327-4336.

-86 Perez LM, Bernal A, San Martin N, Galvez BG: Obese-derived ASCs show impaired migration and angiogenesis properties. Arch Physiol Biochem 2013;119:195-201.

-87 Pachon-Pena G, Serena C, Ejarque M, Petriz J, Duran X, Oliva-Olivera W, Simo R, Tinahones FJ, FernandezVeledo S, Vendrell J: Obesity Determines the Immunophenotypic Profile and Functional Characteristics of Human Mesenchymal Stem Cells From Adipose Tissue. Stem Cells Transl Med 2016;5:464-475.

88 Roldan M, Macias-Gonzalez M, Garcia R, Tinahones FJ, Martin M: Obesity short-circuits stemness gene network in human adipose multipotent stem cells. FASEB J 2011;25:4111-4126.

-89 Perez LM, Bernal A, de Lucas B, San Martin N, Mastrangelo A, Garcia A, Barbas C, Galvez BG: Altered metabolic and stemness capacity of adipose tissue-derived stem cells from obese mouse and human. PLoS One 2015;10:e0123397.

-90 van den Berg SM, Seijkens TT, Kusters PJ, Beckers L, den Toom M, Smeets E, Levels J, de Winther MP, Lutgens E: Diet-induced obesity in mice diminishes hematopoietic stem and progenitor cells in the bone marrow. FASEB J 2016;30:1779-1788.

$\$ 1$ Benites BD, Gilli SC, Saad ST: Obesity and inflammation and the effect on the hematopoietic system. Rev Bras Hematol Hemoter 2014;36:147-151.

92 Cramer C, Freisinger E, Jones RK, Slakey DP, Dupin CL, Newsome ER, Alt EU, Izadpanah R: Persistent high glucose concentrations alter the regenerative potential of mesenchymal stem cells. Stem Cells Dev 2010;19:1875-1884.

93 Ferraro F, Lymperi S, Mendez-Ferrer S, Saez B, Spencer JA, Yeap BY, Masselli E, Graiani G, Prezioso L, Rizzini EL, Mangoni M, Rizzoli V, Sykes SM, Lin CP, Frenette PS, Quaini F, Scadden DT: Diabetes impairs hematopoietic stem cell mobilization by altering niche function. Sci Transl Med 2011;3:104ra101.

-94 Bhatwadekar AD, Glenn JV, Li G, Curtis TM, Gardiner TA, Stitt AW: Advanced glycation of fibronectin impairs vascular repair by endothelial progenitor cells: implications for vasodegeneration in diabetic retinopathy. Invest Ophthalmol Vis Sci 2008;49:1232-1241. 


\section{Cellular Physiology Cell Physiol Biochem 2018;46:1999-2016 \begin{tabular}{l|l} 
DOI: 10.1159/000489440 & and Biochemistry \\
Published online: 1 Vay 02, 2018 & $\begin{array}{l}\text { 2018 The Author(s). Published by S. Karger AG, Basel } \\
\text { www.karger.com/cpb }\end{array}$
\end{tabular}}

Pérez et al.: Disturbed Stem Cell Properties

95 Yaochite JN, de Lima KW, Caliari-Oliveira C, Palma PV, Couri CE, Simoes BP, Covas DT, Voltarelli JC, Oliveira MC, Donadi EA, Malmegrim KC: Multipotent mesenchymal stromal cells from patients with newly diagnosed type 1 diabetes mellitus exhibit preserved in vitro and in vivo immunomodulatory properties. Stem Cell Res Ther 2016;7:14.

-96 Davies LC, Alm JJ, Heldring N, Moll G, Gavin C, Batsis I, Qian H, Sigvardsson M, Nilsson B, Kyllonen LE, Salmela KT, Carlsson PO, Korsgren O, Le Blanc K: Type 1 Diabetes Mellitus Donor Mesenchymal Stromal Cells Exhibit Comparable Potency to Healthy Controls In vitro. Stem Cells Transl Med 2016;10.5966/ sctm.2015-0272

\$7 Tie G, Messina KE, Yan J, Messina JA, Messina LM: Hypercholesterolemia induces oxidant stress that accelerates the ageing of hematopoietic stem cells. J Am Heart Assoc 2014;3:e000241.

-98 Seijkens T, Hoeksema MA, Beckers L, Smeets E, Meiler S, Levels J, Tjwa M, de Winther MP, Lutgens E: Hypercholesterolemia-induced priming of hematopoietic stem and progenitor cells aggravates atherosclerosis. FASEB J 2014;28:2202-2213.

99 Tait AS, Butts CL, Sternberg EM: The role of glucocorticoids and progestins in inflammatory, autoimmune, and infectious disease. J Leukoc Biol 2008;84:924-931.

100 Feldman BJ: Glucocorticoids influence on mesenchymal stem cells and implications for metabolic disease. Pediatr Res 2009;65:249-251.

101 Kang H, Chen H, Huang P, Qi J, Qian N, Deng L, Guo L: Glucocorticoids impair bone formation of bone marrow stromal stem cells by reciprocally regulating microRNA-34a-5p. Osteoporos Int 2016;27:14931505.

102 Hardy R, Cooper MS: Glucocorticoid-induced osteoporosis - a disorder of mesenchymal stromal cells? Front Endocrinol (Lausanne) 2011;2:24.

103 Serhan CN, Savill J: Resolution of inflammation: the beginning programs the end. Nat Immunol 2005;6:1191-1197.

104 Coutinho AE, Chapman KE: The anti-inflammatory and immunosuppressive effects of glucocorticoids, recent developments and mechanistic insights. Mol Cell Endocrinol 2011;335:2-13.

105 Shacter E, Weitzman SA: Chronic inflammation and cancer. Oncology (Williston Park) 2002;16:217-226, 229; discussion 230-212.

106 Boissier MC: Cell and cytokine imbalances in rheumatoid synovitis. Joint Bone Spine 2011;78:230-234.

107 Papadaki HA, Kritikos HD, Gemetzi C, Koutala H, Marsh JC, Boumpas DT, Eliopoulos GD: Bone marrow progenitor cell reserve and function and stromal cell function are defective in rheumatoid arthritis: evidence for a tumor necrosis factor alpha-mediated effect. Blood 2002;99:1610-1619.

108 Mohanty ST, Kottam L, Gambardella A, Nicklin MJ, Coulton L, Hughes D, Wilson AG, Croucher PI, Bellantuono I: Alterations in the self-renewal and differentiation ability of bone marrow mesenchymal stem cells in a mouse model of rheumatoid arthritis. Arthritis Res Ther 2010;12:R149.

109 El-Badri NS, Hakki A, Ferrari A, Shamekh R, Good RA: Autoimmune disease: is it a disorder of the microenvironment? Immunol Res 2008;41:79-86.

110 Gao L, Bird AK, Meednu N, Dauenhauer K, Liesveld J, Anolik J, Looney RJ: Bone Marrow-Derived Mesenchymal Stem Cells From Patients With Systemic Lupus Erythematosus Have a Senescence-Associated Secretory Phenotype Mediated by a Mitochondrial Antiviral Signaling Protein-Interferon-beta Feedback Loop. Arthritis Rheumatol 2017;69:1623-1635.

111 Nie Y, Lau C, Lie A, Chan G, Mok M: Defective phenotype of mesenchymal stem cells in patients with systemic lupus erythematosus. Lupus 2010;19:850-859.

112 Trosko JE: Review paper: cancer stem cells and cancer nonstem cells: from adult stem cells or from reprogramming of differentiated somatic cells. Vet Pathol 2009;46:176-193.

113 Kuhn NZ, Tuan RS: Regulation of stemness and stem cell niche of mesenchymal stem cells: implications in tumorigenesis and metastasis. J Cell Physiol 2010;222:268-277.

114 Korbut E, Ptak-Belowska A, Brzozowski T: Mechanisms promoting physiological cells progression into tumorigenesis. J Physiol Pharmacol 2012;63:565-570.

115 Perry JM, Li L: Disrupting the stem cell niche: good seeds in bad soil. Cell 2007;129:1045-1047.

116 Wang Z, Yang H, Wang X, Wang L, Cheng Y, Zhang Y, Tu Y: The molecular mechanism and regulatory pathways of cancer stem cells. Cancer Translational Medicine 2016;2:147-153.

117 Bao B, Ahmad A, Azmi AS, Ali S, Sarkar FH: Overview of cancer stem cells (CSCs) and mechanisms of their regulation: implications for cancer therapy. Curr Protoc Pharmacol 2013;Chapter 14:Unit 1425. 


\section{Cellular Physiology Cell Physiol Biochem 2018;46:1999-2016

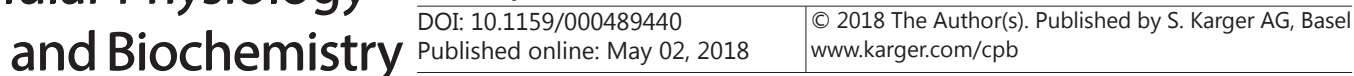

Pérez et al.: Disturbed Stem Cell Properties

118 Schepers K, Campbell TB, Passegue E: Normal and leukemic stem cell niches: insights and therapeutic opportunities. Cell Stem Cell 2015;16:254-267.

119 Lapidot T, Sirard C, Vormoor J, Murdoch B, Hoang T, Caceres-Cortes J, Minden M, Paterson B, Caligiuri MA, Dick JE: A cell initiating human acute myeloid leukaemia after transplantation into SCID mice. Nature 1994;367:645-648.

120 Yohe S: Molecular Genetic Markers in Acute Myeloid Leukemia. J Clin Med 2015;4:460-478.

121 Gerber JM, Gucwa JL, Esopi D, Gurel M, Haffner MC, Vala M, Nelson WG, Jones RJ, Yegnasubramanian S: Genome-wide comparison of the transcriptomes of highly enriched normal and chronic myeloid leukemia stem and progenitor cell populations. Oncotarget 2013;4:715-728.

122 Testa U: Leukemic Stem Cells in Acute Lymphoblastic Leukemia, 2015.

123 Xiao W, Mohseny AB, Hogendoorn PC, Cleton-Jansen AM: Mesenchymal stem cell transformation and sarcoma genesis. Clin Sarcoma Res 2013;3:10.

124 Jedlicka P: Ewing Sarcoma, an enigmatic malignancy of likely progenitor cell origin, driven by transcription factor oncogenic fusions. Int J Clin Exp Pathol 2010;3:338-347.

125 Dontu G, Al-Hajj M, Abdallah WM, Clarke MF, Wicha MS: Stem cells in normal breast development and breast cancer. Cell Prolif 2003;36 Suppl 1:59-72.

126 Al-Hajj M, Wicha MS, Benito-Hernandez A, Morrison SJ, Clarke MF: Prospective identification of tumorigenic breast cancer cells. Proc Natl Acad Sci U S A 2003;100:3983-3988.

127 Young NS, Calado RT, Scheinberg P: Current concepts in the pathophysiology and treatment of aplastic anemia. Blood 2006;108:2509-2519.

128 Chatterjee S, Dutta RK, Basak P, Das P, Das M, Pereira JA, Chaklader M, Chaudhuri S, Law S: Alteration in marrow stromal microenvironment and apoptosis mechanisms involved in aplastic anemia: an animal model to study the possible disease pathology. Stem Cells Int 2010;2010:932354.

129 Li J, Lu S, Yang S, Xing W, Feng J, Li W, Zhao Q Wu H, Ge M, Ma F, Zhao H, Liu B, Zhang L, Zheng Y, Han ZC: Impaired immunomodulatory ability of bone marrow mesenchymal stem cells on CD4(+) T cells in aplastic anemia. Results Immunol 2012;2:142-147.

130 Burkhalter MD, Rudolph KL, Sperka T: Genome instability of ageing stem cells--Induction and defence mechanisms. Ageing Res Rev 2015;23:29-36.

131 Blasco MA: Telomere length, stem cells and aging. Nat Chem Biol 2007;3:640-649.

132 Krauss SR, de Haan G: Epigenetic perturbations in aging stem cells. Mamm Genome 2016;27:396-406.

133 Ahlqvist KJ, Suomalainen A, Hamalainen RH: Stem cells, mitochondria and aging. Biochim Biophys Acta 2015;1847:1380-1386.

134 Angelova PR, Barilani M, Lovejoy C, Dossena M, Vigano M, Seresini A, Piga D, Gandhi S, Pezzoli G, Abramov AY, Lazzari L: Mitochondrial dysfunction in Parkinsonian mesenchymal stem cells impairs differentiation. Redox Biol 2018;14:474-484.

135 Thorley M, Malatras A, Duddy W, Le Gall L, Mouly V, Butler Browne G, Duguez S: Changes in Communication between Muscle Stem Cells and their Environment with Aging. J Neuromuscul Dis 2015;2:205-217.

136 Murphy T, Thuret S: The systemic milieu as a mediator of dietary influence on stem cell function during ageing. Ageing Res Rev 2015;19:53-64.

137 Geiger H, de Haan G, Florian MC: The ageing haematopoietic stem cell compartment. Nat Rev Immunol 2013;13:376-389.

138 Fehrer C, Lepperdinger G: Mesenchymal stem cell aging. Exp Gerontol 2005;40:926-930.

139 Sethe S, Scutt A, Stolzing A: Aging of mesenchymal stem cells. Ageing Res Rev 2006;5:91-116.

140 Zhu M, Kohan E, Bradley J, Hedrick M, Benhaim P, Zuk P: The effect of age on osteogenic, adipogenic and proliferative potential of female adipose-derived stem cells. J Tissue Eng Regen Med 2009;3:290-301.

141 Sambasivan R, Tajbakhsh S: Adult skeletal muscle stem cells. Results Probl Cell Differ 2015;56:191-213.

142 Asakura A: Stem cells in adult skeletal muscle. Trends Cardiovasc Med 2003;13:123-128.

143 Felice F, Barsotti MC, Poredos P, Balbarini A, Di Stefano R: Effect of aging on metabolic pathways in endothelial progenitor cells. Curr Pharm Des 2013;19:2351-2365.

144 Williamson K, Stringer SE, Alexander MY: Endothelial progenitor cells enter the aging arena. Front Physiol 2012;3:30.

145 Lugert S, Basak O, Knuckles P, Haussler U, Fabel K, Gotz M, Haas CA, Kempermann G, Taylor V, Giachino C: Quiescent and active hippocampal neural stem cells with distinct morphologies respond selectively to physiological and pathological stimuli and aging. Cell Stem Cell 2010;6:445-456. 


\section{Cellular Physiology Cell Physiol Biochem 2018;46:1999-2016

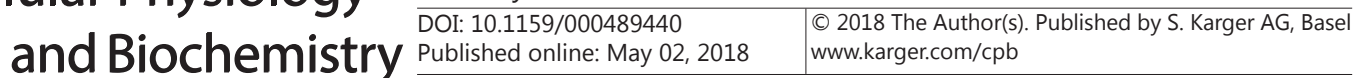

Pérez et al.: Disturbed Stem Cell Properties

146 Onate B, Vilahur G, Camino-Lopez S, Diez-Caballero A, Ballesta-Lopez C, Ybarra J, Moscatiello F, Herrero J, Badimon L: Stem cells isolated from adipose tissue of obese patients show changes in their transcriptomic profile that indicate loss in stemcellness and increased commitment to an adipocyte-like phenotype. BMC Genomics 2013;14:625.

147 Wu CL, Diekman BO, Jain D, Guilak F: Diet-induced obesity alters the differentiation potential of stem cells isolated from bone marrow, adipose tissue and infrapatellar fat pad: the effects of free fatty acids. Int J Obes (Lond) 2013;37:1079-1087.

148 Ninomiya E, Hattori T, Toyoda M, Umezawa A, Hamazaki T, Shintaku H: Glucocorticoids promote neural progenitor cell proliferation derived from human induced pluripotent stem cells. Springerplus 2014;3:527.

149 Sun LY, Zhang HY, Feng XB, Hou YY, Lu LW, Fan LM: Abnormality of bone marrow-derived mesenchymal stem cells in patients with systemic lupus erythematosus. Lupus 2007;16:121-128.

150 Hardeland R: Melatonin in aging and disease -multiple consequences of reduced secretion, options and limits of treatment. Aging Dis 2012;3:194-225.

151 Zhu P, Liu J, Shi J, Zhou Q, Liu J, Zhang X, Du Z, Liu Q Guo Y: Melatonin protects ADSCs from ROS and enhances their therapeutic potency in a rat model of myocardial infarction. J Cell Mol Med 2015;19:22322243.

152 Jeanson NT, Scadden DT: Vitamin D receptor deletion leads to increased hematopoietic stem and progenitor cells residing in the spleen. Blood 2010;116:4126-4129.

153 de Resende MM, Stodola TJ, Greene AS: Role of the renin angiotensin system on bone marrow-derived stem cell function and its impact on skeletal muscle angiogenesis. Physiol Genomics 2010;42:437-444.

154 Ray R, Novotny NM, Crisostomo PR, Lahm T, Abarbanell A, Meldrum DR: Sex steroids and stem cell function. Mol Med 2008;14:493-501.

155 Dulken B, Brunet A: Stem Cell Aging and Sex: Are We Missing Something? Cell Stem Cell 2015;16:588-590. 